\title{
Produção e avaliação da qualidade das barras de cereais elaborada com farinha de facheiro
}

\section{Production and evaluation of the quality of cereal bars made with flour of facheiro}

\author{
José N. V. Deodato ${ }^{*}$, Alfredina dos S. Araújo ${ }^{2}$, Danielle de S. Severo ${ }^{3}$, César C. M. da Silva ${ }^{4}$, Gilcean S. Alves ${ }^{5}$
}

Resumo: As cactáceas constituem um importante elemento da paisagem, apresentando caules suculentos, cobertos por espinhos de diversas formas, tamanhos e dimensões, junto a outras espécies de cactáceas, formam a paisagem típica da região semiárida do Brasil. O facheiro é uma cactácea xerófila, robusta, pouco ramificada, de cor verde-escura, armada de espinhos agudos; com flores grandes isoladas e altas. A proposta do trabalho foi elaborar barras de cereais com farinhas da casca e da polpa do facheiro e determinar as características microbiológicas e físico-químicas. Foram preparadas quatro formulações (5, 10, 15 e 20\%) de cada farinha, variando-se a quantidade adicionada à formulação básica das barras de cereais. Os resultados das análises microbiológicas atenderam aos padrões exigidos pela legislação vigente, apresentando resultados negativos para coliforme a $45^{\circ} \mathrm{C}$ e Salmonella sp. Nos resultados físico-químicos apresentaram baixos valores de umidade e cinzas, elevado teores de lipídeos e sólidos solúveis totais, quantidades razoáveis de proteínas. Dessa forma, as barras de cereais com adição de farinha do facheiro é um alimento que pode ser ingeridos pela população.

Palavras-chaves: Cactácea, Alimentação humana, Aditivo, Qualidade.

\begin{abstract}
The cacti are an important element of the landscape, with succulent stems, covered with spines of different shapes, sizes and dimensions, along with other cactus species, form the typical landscape of the semi-arid region of Brazil. The facheiro is a cactaceous xerófila, rugged, sparsely branched, dark green color, armed with sharp thorns; with large isolated and tall flowers. The purpose of this study was to develop cereal bars with flour peel and facheiro pulp and determine the microbiological and physico-chemical characteristics. Four formulations (5, 10, 15 and 20\%) for each meal, varying the amount added to the basic formulation of the cereal bars. The results of the microbiological analyzes met the standards required by law, with negative results for coliform bacteria at $45^{\circ} \mathrm{C}$ and Salmonella sp. The physicochemical results showed low values of moisture and ash, high levels of lipids and total soluble solids, reasonable amounts of protein. Thus, the cereal bars with facheiro flour added is a food that can be eaten by the population.
\end{abstract}

Key words: Cactaceous, Food, Additive, Quality.

\footnotetext{
*Autor para correspondência

Recebido para publicação em 04/06/2015; aprovado em 01/08/2015

${ }^{1}$ Mestre, UFCG, Pombal; (83) 99976-9436, jnvdeodato@ hotmail.com.

${ }^{2}$ Doutora, UFCG, alfredina@ccta.ufcg.edu.br

${ }^{3}$ Graduada, UFCG, danni_severo@hotmail.com

${ }^{4}$ Graduando, UFCG, cesaralimentos@gmail.com

${ }^{5}$ Doutor, IFPB, biopb@hotmail.com
} 


\section{INTRODUÇÃO}

O Brasil é considerado o terceiro maior centro de diversidade da família Cactaceae totalizando aproximadamente 200 espécies (SOUZA; LORENZI, 2005), sendo muitas destas espécies endêmicas da Caatinga Nordestina, e que necessitam de maiores estudos (TAYLOR; ZAPPI, 2004).

De acordo com Castro (2008), As cactáceas constituem uma família eclética de plantas, podendo ser encontrados espécimes arbóreos e rasteiros, A diversidade existente na família se expressa em diversas características, quer sejam: anatômicas, fisiológicas, morfológicas e adaptativas, Com facilidade podem-se avistar indivíduos da família ao longo das margens das estradas que ligam os municípios nordestinos, onde se destacam pela sua importância como fonte de renda, sendo as várias espécies cultivadas para fins ornamentais, forrageiros e medicinais. Esta multiplicidade de usos dá-se pelo seu endemismo na região semiárida.

Sendo denominada de Semiárido, Uma vasta área de 980 mil quilômetros quadrados, que corresponde a $60 \%$ de toda a Região Nordeste e parte de Minas Gerais. É nesse imenso território onde ocorre, naturalmente, uma grande e diversificada população de cactos, a maioria dotada de espinhos, representados por mais de vinte diferentes espécies. (PINHEIRO et al., 2005). Cresce em solos pedregosos e, junto a outras espécies de cactáceas, forma a paisagem típica da região semiárida do Brasil, sendo encontrado nos estados do Piauí, Ceará, Rio Grande do Norte, Paraíba, Pernambuco, Alagoas, Sergipe, Bahia e norte de Minas Gerais (SILVA, 2009). Que correspondem aproximadamente a 8\% do território do Brasil. É uma terra marcada pela irregularidade das chuvas, determinando longos períodos de secas, com forte deficiência hídrica e graves consequências sociais para seus habitantes, que apresentam elevada dependência dos recursos naturais e os piores indicadores sociais do país (FERREIRA, 1994).

O seu bioma é provavelmente, o menos estudado em relação à flora e à fauna, e um dos que têm sofrido maior degradação, pelo uso desordenado e predatório, nos últimos 400 anos (ARAÚJO, 2007). Assim, em relação ao meio ambiente do semiárido, algumas das linhas de pesquisa que devem ser priorizadas são aquelas voltadas para um melhor conhecimento da biodiversidade, e do seu uso pelas populações locais, que deveriam se constituir na base de qualquer programa que vise o desenvolvimento sustentável da região. Isso se justifica pelo fato do semiárido apresentar um dos biomas mais particulares do mundo, em composição e adaptações às condições do meio (DUARTE, 1992).

O facheiro (Pilosocereus chrysostele) é uma espécie desta família de abrangente ocorrência no Semiárido Nordestino. É uma planta perene, arbustiva, robusta, de tronco ereto com galhos laterais, porém pouco ramificada, de coloração verde escura, que apresentam espinhos agudos e flores grandes, alvas e isoladas vegetando nos piores tipos de solo, até mesmo nas rochas onde existe um pouco de areia, e resiste à vários meses de seca, época em que serve de alimento para o gado (OLIVEIRA et al, 2007).

De acordo com Lima (2006) Por ser um produto com teor de água relativamente elevado, o caule de facheiro precisa ser avaliado quanto ao seu comportamento quando submetido à secagem, processamento importante para a exploração comercial de produtos agrícolas.

Segundo Júnior (2008) A exploração econômica do facheiro através do processamento de farinha tendo como finalidade o emprego na alimentação humana pode representar uma alternativa de significância ecológica, econômica e social para a região do semiárido. Apesar de essa cactácea ser utilizada há bastante tempo, principalmente na alimentação animal como suplemento alimentar nos longos períodos de secas que ocorrem na região, não existe relatos científicos do seu emprego na alimentação humana na forma de produtos industrializados elaborados a partir da farinha.

As farinhas de cactáceas (como a da polpa e da casca, apresentadas neste trabalho) podem ser utilizadas como alternativa para substituição parcial da farinha de trigo na elaboração de barras de cereais, cookies, bolos e, também, como fonte enriquecedora de nutrientes nas vitaminas.

$\mathrm{O}$ melhoramento da qualidade da farinha representa um acréscimo na qualidade do produto, uma oportunidade para se agregar valor ao mesmo (SMANHOTTO, 2006).

No Brasil a diferenciação para cada farinha e sua especialidade, não tem tal relevância, portanto a otimização das farinhas é de grande importância, para que assim cada tipo de farinha atenda as exigências dos determinados produtos finais (GUTKOSKI; et al.; 1999).

A demanda por alimentos nutritivos e seguros está crescendo mundialmente, e a ingestão de alimentos balanceados é a maneira correta de evitar ou mesmo corrigir problemas de saúde, como: obesidade, diabetes, desnutrição, cardiopatias, entre outros que têm origem, em grande parte, nos erros alimentares, As barras de cereais atendem a esta tendência e são elaboradas a partir da extrusão da massa de cereais de sabor adocicado e agradável, fonte de vitaminas, sais minerais, fibras, proteínas e carboidratos complexos (IZZO; NINESS, 2001).

As barras de cereais são alimentos de fácil consumo, requerem pouco ou nenhum preparo e durante muito tempo seus valores nutritivos foram pouco enfatizados (ESTEVEZ, 1995). Os cereais em barra são uma classe de produtos de confeitaria, de forma retangular, vendidos em embalagens individuais e têm apresentado um rápido crescimento no mercado (IZZO, 2001; SKLIUTAS, 2002). Os principais aspectos considerados na elaboração desse produto incluem: a escolha do cereal, a seleção do carboidrato apropriado (de forma a manter o equilíbrio entre o sabor e a vida de prateleira), o enriquecimento com vários nutrientes e sua estabilidade no processamento. Também tem sido considerado o valor nutricional, sendo preferidos os com alto conteúdo de fibras e baixo teor ou isentos de gordura, porém com alto aporte energético (ESCOBAR et al.; 1998). Portanto o objetivo desse trabalho foi Elaborar uma farinha à partir da cactácea do facheiro e desenvolver barras de cereais com diferentes (concentrações) teores da farinha de facheiro.

\section{MATERIAL E MÉTODOS}

As farinhas foram elaboradas a partir do caule e da casca do facheiro totalmente seco em estufas. Os facheiros foram provenientes da região da serra do Moleque no sitio Mocambo, zona rural de Pombal. As produções das farinhas, 
em grandes quantidades, foram realizadas nas dependências do Centro Vocacional e Tecnológico de Pombal (CVT).

\section{Matéria-prima}

Foram utilizados os seguintes ingredientes para a formulação da barra de cereais: aveia fina, flocos de trigo, açúcar refinado, farinha integral, farinha de facheiro (polpa e casca), castanha do Pará, gergelim, linhaça, gordura vegetal hidrogenada $(\mathrm{GVH})$ Primor® e água.

\section{Formulações das barras de cereais}

Para a elaboração das amostras utilizou-se uma receita base de barra de cereal, com aveia fina, focos de trigo, açúcar refinado, farinha integral, gergelim, linhaça, castanha do Pará, gordura vegetal hidrogenada e água. Além das farinhas da polpa e da casca do facheiro distribuídas nas seguintes concentrações: Amostra $1-95 \%$ de farinha de trigo e 5\% da farinha obtido do facheiro, Amostra $2-90 \%$ de farinha de trigo e $10 \%$ da farinha de facheiro, Amostra 3 $85 \%$ de farinha de trigo e $15 \%$ facheiro, Amostra $4-80 \%$ de farinha de trigo e $20 \%$ de farinha de facheiro. Cada receita compreendeu as seguintes quantidades de cada ingrediente: $60 \mathrm{~g}$ de aveia fina, $60 \mathrm{~g}$ de flocos de trigo, $125 \mathrm{~g}$ de $(\mathrm{GVH})$ primor, $100 \mathrm{~g}$ de açúcar refinado, $15 \mathrm{~g}$ de castanha do Pará, $25 \mathrm{~g}$ de gergelim, $25 \mathrm{~g}$ de linhaça e quatro colheres de água. Logo após colocou-se todos os ingredientes numa tigela e misturou-se até ficar uma mistura homogênea. Em seguida a massa foi pra uma fôrma retangular $(32 \mathrm{~cm}$ x $20 \mathrm{~cm})$ forrada com papel alumínio e levado a forno pré-aquecido por 30 minutos. Ao final as barras se apresentavam com peso médio de $25 \mathrm{~g}$ cada, sendo embaladas e armazenadas envoltas por plástico filme.

\section{Avaliações microbiológicas}

Após a obtenção das barras de cereais foram realizadas as seguintes avaliações da qualidade microbiológica, seguindo a Resolução - RDC n ${ }^{\circ}$ 12, de 2001, que define o Regulamento Técnico para os padrões microbiológicos para alimentos (BRASIL, 2001). Onde foram efetuadas as análises de Coliformes Totais e Termotolerantes e Salmonela spp/25g.

\section{Avaliações físico-químicas}

Foram realizadas as seguintes análises físico-químicas: umidade (\%), cinzas (\%), Proteínas (\%), lipídeos (\%), pH, acidez e sólidos solúveis totais.

Umidade (\%): Foram determinadas pelo método gravimétrico que se baseia na perda de peso das amostras submetidas a aquecimento à temperatura de $105^{\circ} \mathrm{C}$, em estufa de secagem, até peso constante, seguindo a metodologia 012/IV do Instituto Adolf Lutz (2008).

Cinzas (\%): Realizou-se utilizando o método gravimétrico, fundamentado na calcinação da matéria orgânica em forno mufla à temperatura de $550^{\circ} \mathrm{C}$ até que ocorra a combustão total da matéria orgânica e foram determinadas segundo o método 018/IV do Instituto Adolf Lutz (2008).

Proteínas (\%): Os teores de proteínas foram determinados através do método Kjedahl, 036/IV descrito pelo Instituto Adolfo Lutz (2008). Foi realizado o processo de digestão em bloco digestor, com o auxílio de tubos para digestão, nos quais continham $0,2 \mathrm{~g}$ das amostras, 1,5 g de substância catalítica e $3 \mathrm{~mL}$ de ácido sulfúrico $\mathrm{PA}$. O aquecimento da capela ocorreu de forma gradativa, com temperatura inicial de $50{ }^{\circ} \mathrm{C}$ e final de $400{ }^{\circ} \mathrm{C}$. Para a destilação foi utilizado fenolftaleína como indicador e aos tubos foral adicionados 30 $\mathrm{mL}$ de água destilada, $5 \mathrm{~mL}$ de hidróxido de sódio $63 \%$. Sofreram destilação em um destilador de nitrogênio e as soluções foram coletadas em recipientes contendo ácido bórico e os indicadores para, então, serem tituladas com solução de ácido clorídrico a 0,1 Molar (M).

Lipídios: A análise de lipídios foi determinada através do aparelho extrator de Soxhlet, seguindo o método descrito 033/IV do Instituto Adolf Lutz (2008). Foram empregadas $5 \mathrm{~g}$ das amostras e hexano como solvente extrator. $\mathrm{O}$ sistema foi aquecido por cerca de 6 horas e em seguida submetido à secagem em estufa a $105{ }^{\circ} \mathrm{C}$ durante 1 hora. Assim, procedidas às pesagens.

pH: Foi determinado através do método potenciométrico, com pHmetro de bancada da marca Lucadema e modelo mPA, previamente calibrado com solução tampão de $\mathrm{pH} 4,00$ e 7,00. Seguindo o método 017/IV do Instituto Adolf Lutz (2008). e os resultados foram expressos em porcentagem $(\mathrm{p} / \mathrm{p})$.

Acidez: Determinado de acordo com o método 016/ IV do Instituto Adolf Lutz (2008). Onde foram adicionada3 gotas da solução fenolftaleína e titula com solução de hidróxido de sódio 0,1 Molar $(\mathrm{M})$, até coloração rósea.

O teor de sólidos solúveis totais ( ${ }^{\circ}$ Brix) foi determinado de acordo com a metodologia recomendada pelo IAL (2008). Assim, mediu-se cerca de $1 \mathrm{~g}$ da amostra juntamente com 2 $\mathrm{mL}$ de água foi macerada até a máxima dissolução, filtrada e feita a leitura ( ${ }^{\circ}$ Brix) em um refratômetro digital modelo Reichert AR 200, com compensação automática de temperatura.

\section{RESULTADOS E DISCUSSÃO}

$\mathrm{Na}$ tabela 01 estão os resultados para coliformes e salmonela sp. e apresentaram-se ausentes em todas as amostras de barras de cereais elaboradas nas concentrações de $5,10,15$, e $20 \%$ de farinha da polpa e da casca do facheiro, demonstram que não ocorreu falhas de higienização no processamento e na manipulação dos produtos.

Tabela 01: resultados das analises microbiológicas das barras de cereais

\begin{tabular}{|c|c|c|c|}
\hline \multirow[b]{2}{*}{$\begin{array}{l}\text { Barras de } \\
\text { cereais }\end{array}$} & \multicolumn{3}{|c|}{ Parâmetros microbiológicos } \\
\hline & $\begin{array}{l}\text { Coliformes } \\
45^{\circ} \mathrm{C}\end{array}$ & $\mathrm{a}$ & Salmonela $s p$. \\
\hline P $5 \%$ & Ausente & & Ausente \\
\hline P $10 \%$ & Ausente & & Ausente \\
\hline P $15 \%$ & Ausente & & Ausente \\
\hline P $20 \%$ & Ausente & & Ausente \\
\hline C $5 \%$ & Ausente & & Ausente \\
\hline C $10 \%$ & Ausente & & Ausente \\
\hline C $15 \%$ & Ausente & & Ausente \\
\hline C $20 \%$ & Ausente & & Ausente \\
\hline
\end{tabular}

Não foi detectada a presença de Salmonella sp em nenhuma amostra da barras de cereais, podendo ser assim considerada própria para o consumo humano. A salmonella é uma bactéria entérica responsável por graves intoxicações 
alimentares, sendo um dos principais agentes envolvidos em surtos registrados em vários países'(MAIJALA et al.; 2005; TESSARI et al.; 2003). A sua presença em alimentos é um relevante problema de saúde pública que não deve ser tolerado nos países desenvolvidos, e principalmente nos países em desenvolvimento, porque os sinais e sintomas podem ser mal diagnosticados, sobrecarregando ainda mais todo o sistema de saúde (FLOWERES, 1988).

Tabela 02: Composição físico-química da barra de cereal formulada com $5,10,15$, e $20 \%$ da farinha da polpa do facheiro.

\begin{tabular}{c|c|c|c|c}
\hline \multirow{2}{*}{ Constituintes } & \multicolumn{4}{|c}{ Formulações } \\
\cline { 2 - 5 } & $5 \%$ & $10 \%$ & $15 \%$ & $20 \%$ \\
\hline Umidade (\%) & 4,90 & 5,19 & 1,60 & 4,97 \\
\hline Cinzas (\%) & 1,62 & 1,80 & 2,00 & 2,12 \\
\hline Proteínas (\%) & 1,99 & 1,24 & 2,16 & 2,10 \\
\hline Lipídeos (\%) & 19,54 & 19,34 & 19,30 & 17,43 \\
\hline $\mathrm{pH}$ & 5,90 & 6,08 & 5,77 & 6,01 \\
\hline $\begin{array}{c}\text { Acidez } \\
(\mathrm{g} / 100 \mathrm{~mL})\end{array}$ & 0,13 & 0,10 & 0,10 & 0,10 \\
\hline $\begin{array}{c}\text { Sólidos Solúveis } \\
\left({ }^{\circ} \text { Brix }\right)\end{array}$ & 16,0 & 25,0 & 35,0 & 35,5 \\
\hline
\end{tabular}

Constatou-se que as umidades encontradas nas barras de cereais elaboradas com a farinha da polpa do facheiro variou de (1,60 a 5,19\%), podendo estes produtos seres considerados de baixas umidades que possibilitam um maior tempo de vida de prateleira aos produtos, ao mesmo tempo em que garante a textura característica de barra de cereal.

As barras de cereais apresentaram baixos níveis nos teores de cinzas em ambas formulações, no entanto estes valores são superiores aos encontrados por Brito et al., (2004) que encontrou em barras de cereais caseiras valor de $1,13 \%$.

Os valores de proteínas das barras de cereais foram bastante inferiores aos encontrados por Freitas e Moretti (2006) que ao analisar barra de cereal funcional obteve valor de $15,41 \%$ bem como inferior ao valor de barras de cereais encontradas no mercado que é de $4,4 \%$.

Quantos aos teores de lipídeos verificados não apresentaram diferenças entre as formulações das barras de cereais. As formulações das barras de cereais apresentaram elevados conteúdos de lipídeos. Este fato deve-se ao alto teor de lipídeos da polpa, bem como aos ingredientes utilizados na sua formulação.

Os teores de lipídeos das barras de cereais elaboradas com a farinha da casca do facheiro foram maiores do que as elaboradas com a polpa, devido ao elevado teor de lipídeo da mesma.

Os teores de Sólidos Solúveis das barras de cereais aumentaram a medida que a concentração de farinha foi elevada.

Os valores de acidez das barras de cereais mantiveram-se praticamente constantes nas formulações e os valores de $\mathrm{pH}$ obteve pequenas variações $(5,77$ a 6,08$)$.
Tabela 03: Composição físico-química da barra de cereal formulada com $5,10,15$, e $20 \%$ da farinha da casca do facheiro.

\begin{tabular}{c|l|l|l|l}
\hline \multirow{2}{*}{ Constituintes } & \multicolumn{4}{|c}{ Formulações } \\
\cline { 2 - 5 } & $5 \%$ & $10 \%$ & \multicolumn{1}{c}{$15 \%$} \\
\hline Umidade (\%) & 2,21 & 7,20 & 2,33 & 4,33 \\
\hline Cinzas (\%) & 1,82 & 1,83 & 2,05 & 2,19 \\
\hline Proteínas (\%) & 1,25 & 2,51 & 1,69 & 1,44 \\
\hline Lipídeos (\%) & 14,17 & 22,64 & 28,78 & 27,35 \\
\hline $\mathrm{pH}$ & 5,58 & 5,94 & 5,52 & 5,85 \\
\hline $\begin{array}{c}\text { Acidez } \\
(\mathrm{g} / 100 \mathrm{~mL})\end{array}$ & 0,10 & 0,10 & 0,10 & 0,06 \\
\hline $\begin{array}{c}\text { Sólidos Solúveis } \\
\left({ }^{\circ} \text { Brix }\right)\end{array}$ & 19 & 23 & 24 & 23,5 \\
\hline
\end{tabular}

\section{CONCLUSÕES}

A qualidade microbiológica das barras de cereais com farinha da casca e da polpa do facheiro apresentou dentro dos padrões exigidos pela legislação brasileira para elaboração dos produtos;

As amostras contendo farinha da casca e da polpa de facheiro (FCF e FPF) possuem um percentual significativo de proteínas, lipídios e cinzas, além de ser, principalmente, uma excelente fonte de fibras, indicando que o produto é favorável do ponto de vista nutricional.

Quanto aos teores de cinzas encontrados nas barras de cereais, pode-se observar que quanto maior a concentração da farinha de facheiro maior foi o seu resíduo, assumindo assim uma característica natural do produto.

Referencial teórico

\section{REFERÊNCIAS BIBLIOGRÁFICAS}

ARAÚJO, L.V.C. Composição florística, fitossociológica e influência dos solos na estrutura da vegetação em uma área de caatinga no semiárido paraibano. 2007. $121 \mathrm{f}$. Tese doutorado - Universidade Federal da Paraíba, Areia, PB, 2007.

BRASIL. RDC n.12 de 02 de janeiro de 2001. Regulamento Técnico sobre Padrões Microbiológicos para Alimentos. Brasília, DF: ANVISA, 2001.

BRITO, I. P.; CAMPOS, J. M.; SOUZA, T. F. L.; WAKIYAMA, C.; AZEREDO, G. A.; elaboração e avaliação global de barra de cereais Caseira. B.CEBP. Curitiba, v 22, n 1.p.35 a50.,/ jan/jun 2004.

DUARTE, R. Tecnologias apropriadas para a agricultura dependente de chuva no semiárido nordestino: uma avaliação. Cadernos de Estudos Sociais, v.9, n.1, p.4153, 1992.

ESCOBAR, B. A.; ESTÉVEZ, A. M.; TEPPER, A. L.; AGUAYO, M. R. Características nutricionales de barras de cereales y maní. Archivos Latino Americanos de Nutricion, v. 48, n. 2, p. 156-159, 1998.

ESTEVEZ, A. M.; ESCOBAR, B.; VASQUEZ, E. Cereal and nut bars, nutricional quality and storage stability. Plant 
Foods for Human Nutrition, v. 47, n. 4, p. 309-317, 1995.

FERREIRA, L.A. Consumo e fluxos de produtos florestais no setor industrial/comercial do estado da Paraíba. JoãoPessoa:PNUD/FAO/IBAMA/UFPB/GOV.PARAIB A, $1994.61 \mathrm{p}$.

Floweres FL. Salmonella. Food Technology 1988; 42(4):182-185.

FREITAS, D. G. C; MORETTI, R. H. Caracterização e avaliação sensorial de barra de cereais funcional de alto teor protéico e vitamínico. Ciência e Tecnologia de Alimentos, Campinas, n.26 v2. p 318-324, abr.-jun. 2006.

GUTKOSKI, L.C., ANTUNES, E., ROMAN, I.T. Avaliação do grau de extração de farinhas de trigo e de milho em moinho tipo colonial. Boletim Ceppa, Curitiba, v.17, n.2, p.153-166, 1999.

INSTITUTO ADOLFO LUTZ Métodos físicos químicos para análise de alimentos. 4. ed. versão digital. São Paulo: Secretaria do Estado de Saúde, 2008. 1018p.

IZZO, M. \& NINESS, K. Formulating Nutrition Bars with Inulin and Oligofructose. Cereal Foods World, v. 46, n. 3, p. 102-105, 2001.

JÚNIOR, W. E. F. Carboidratos: Estrutura, Propriedades e Funções. ConCeitos CientífiCos em Destaque, n.29, agosto de 2008 .

LIMA, E. E. Produção e armazenamento da farinha. 2006. (Dissertação Mestrado em Engenharia Agrícola) Universidade Federal de Campina Grande, 2006.
Maijala R, Ranta J, Seuna E. The efficiency of the Finnish Salmonella Control Control2005; 16(8):669-675.

Programme. Food

OLIVEIRA, F. M. N.; FIGUEIRÊDO, R. M. F.; QUEROZ, A. J. M.; ALMEIDA, C. A.; Caracterização físicoquímica das polpas dos ramos do mandacaru. Caatinga, v.20, n.4, p.89-92, 2007.

SILVA, L. R.; ALVES, R. E.; Caracterização físico-quimica de frutos de "mandacaru". Rer. Acad., Ciênc. Agrár. Ambient., Curitiba, v.7 n.2, p. 199-205, abr./jun. 2009.

SKLIUTAS, A. R. SKLIUTAS, A. R. Estudo do desenvolvimento de barra dietética de cereais $\mathrm{e}$ goiaba desidratada pelo processo de osmose à vácuo com utilização de frutooligossacarídeo. 2002. $116 \mathrm{f}$. Dissertação (Mestrado em Tecnologia de Alimentos), Faculdade de Engenharia de Alimentos, Universidade Estadual de Campinas, UNICAMP, Campinas.

SMANHOTTO, A. et al. Características físicas e fisiológicas na qualidade industrial de cultivares e linhagens de trigo e triticale. Campina grande, 2006.

SOUZA, V. C.; LORENZI, H. Botânica sistemática: guia ilustrado para identificação das famílias de Angiospermas da flora brasileira. Nova Odessa, SP.: Instituto Plantarum, 2005. 639 p.

TAYLOR, N. P.; ZAPPI, D. C. Cacti of Eastern Brazil. Royal Botanic Gardens, Kew. 2004. 499 p.

Tessari ENC, Cardoso ALSP, Castro AGM. Prevalência de Salmonella enteritidis em carcaças de frango industrialmente processadas. Higiene Alimentar 2003; 17(107):52-55. 